\title{
DESCORTINANDO ENFERMAGEM ATRAVÉS DA ARTE: UMA EXPERIÊNCIA INTEGRADORA EM BUSCA DA INTERDISCIPLINARIDADE
}

\author{
Denise Finger \\ Universidade Federal da Fronteira Sul \\ deni.finger@hotmail.com
}

\author{
Jeane Barros de Souza \\ Universidade Federal da Fronteira Sul \\ jeanebarros18@gmail.com \\ Tassiana Potrich \\ Universidade Federal da Fronteira Sul \\ tassiana.potrich@uffs.edu.br
}

\begin{abstract}
Resumo
O profissional da enfermagem necessita abrir novos olhares de atuação profissional, refletindo a interdisciplinaridade e buscando atender aos princípios da transversalidade e integralidade das ações de saúde e cuidado. Assim, o presente artigo objetiva relatar a vivência na construção e realização de atividades integradoras e interdisciplinares no curso de graduação em Enfermagem da Universidade Federal Fronteira Sul (UFFS), campus Chapecó, durante a reformulação de seu Projeto Político Pedagógico (PPP). Trata-se de um relato de experiência acadêmica do Grupo de Trabalho Catavento, o qual lançou, no primeiro semestre de 2015, a proposta da atividade integradora com o tema central "O que eu penso da Enfermagem". Durante a realização da atividade, constatou-se a grande interação entre discentes e docentes de diferentes fases e componentes curriculares. Assim, a atividade foi avaliada pelos participantes como uma ação de extrema importância para a integração do curso, com sugestões de novas estratégias para os próximos semestres.

Palavras-chave: Enfermagem. Arte. Comunicação Interdisciplinar. Educação.
\end{abstract}

\section{REVEALING NURSING THROUGH ART: AN INCLUSIVE EXPERIENCE IN SEARCH INTERDISCIPLINARITY}

\begin{abstract}
The nurse needs to open new professional performance looks, reflecting the interdisciplinary, looking for principles of mainstreaming and integration of health care. So, this article aims to report the experience in the construction and implementation of integrative and interdisciplinary activities in the undergraduate course in Nursing of the Federal University Southern Frontier (UFFS), Chapecó campus during the reformulation of its Political Pedagogical Project (PPP). It is an account of academic experience of the working group "Catavento", which launched in the first half of 2015, the proposal of integrative activity with the theme "What I think of Nursing". While performing the activity, there was great interaction between students and teachers of different phases and curriculum components. Thus, the activity was evaluated by participants as an activity of the utmost importance for the integration of the course, with suggestions for new strategies for the coming half.
\end{abstract}

Keywords: Nursing. Art. Communication. Interdisciplinary. Education.

\section{REVELANDO ENFERMERÍA A TRAVÉS DEL ARTE: UNA EXPERIENCIA INCLUIDO EN BUSCA INTERDISCIPLINARIDAD}

\begin{abstract}
Resumen
La enfermera tiene que abrir nuevas miradas de desempeño profesional, lo que refleja la interdisciplinariedad y la búsqueda de cumplir los principios de la incorporación e integración de las acciones de salud y cuidado. Por lo tanto, este artículo tiene como objetivo informar de la experiencia en la construcción y ejecución de las actividades de integración e interdisciplinarios en el curso de pregrado en Enfermería de la Universidad del Sur de la Frontera Federal (UFFS), Chapecó campus durante la reformulación de su proyecto político pedagógico (PPP). Es un relato de experiencia académica del Grupo de Trabajo Catavento, que puso en marcha en el primer semestre de 2015, la propuesta de la actividad integradora con el tema "Lo que pienso de Enfermería". Durante la realización de la actividad, hubo una gran interacción entre los estudiantes y profesores de diferentes fases y componentes del plan de estudios. Por lo tanto, la actividad fue evaluada por los participantes como una actividad de suma importancia para la integración del curso, con sugerencias para nuevas estrategias para los próximos semestres.

Palavras clave: Enfermería. Arte. Comunicación Interdisciplinaria. Educación.
\end{abstract}


Descortinando enfermagem através da arte: uma experiência integradora em busca da interdisciplinaridade

\section{INTRODUÇÃO}

Diante dos desafios gerenciais do Sistema Único de Saúde (SUS) e das diretrizes curriculares para a formação em Enfermagem, se fazem necessárias discussões e estudos. Com o intuito de possibilitar novos olhares e referenciais, o profissional da enfermagem precisa ser capaz de atender aos princípios da transversalidade e integralidade das ações de saúde e cuidado (RANGEL, et al, 2011). Neste cenário, o enfermeiro necessita abrir caminhos para novos olhares de atuação profissional, buscando avançar para além do cuidado pontual e unidimensional.

A Portaria n. ${ }^{\circ}$ 1.721/94, do Ministério da Educação, define o perfil do enfermeiro na perspectiva de uma formação generalista com competência para o desenvolvimento de suas atividades em quatro áreas fundamentais, denominadas assistência, gerência, ensino e pesquisa (TANAKA, LEITE, 2008). Aliado à isso, para atender as necessidades do cenário atual, o profissional enfermeiro não pode deixar de discutir a interdisciplinaridade durante o curso de Enfermagem, bem como a necessidade da elaboração de currículos que correspondam aos desafios que o mundo lhes mostra.

A interdisciplinaridade na produção e na socialização do conhecimento vem sendo intensamente discutida, principalmente pelos que pesquisam as teorias curriculares e as epistemologias pedagógicas. A literatura evidencia ao menos uma posição consensual sobre o sentido e a finalidade da interdisciplinaridade: busca responder à necessidade de superação da visão fragmentada nos processos de produção e socialização do conhecimento (PELEIAS, et al, 2011).

Neste cenário, é necessário permitir que o discente assuma a posição de agente criador e transformador, com comprometimento, responsabilidade, apto a planejar ações, tomar decisões diante dos fatos e interagir em seu meio. No entanto, por circunstâncias inerentes ao indivíduo, muitos docentes ainda resistem em inovar as suas práticas, se acomodando no método tradicional, onde ele é o transmissor e os discentes são os receptores, decorando conceitos que ao longo do tempo acabarão sendo esquecidos. Deste modo, é essencial que o processo de formação acadêmica oportunize ferramentas e espaços em que o docente possa realizar seu objetivo fundamental, que é ensinar os discentes a serem pensadores, e não transmissores de informação (CURY, 2003).

As práticas interdisciplinares promovem mudanças estruturais, gerando reciprocidade, enriquecimento mútuo, com uma tendência a horizontalização das relações de poder entre os campos envolvidos (VASCONCELOS, 2002). Pata tal, necessita envolvimento dos docentes e 
Descortinando enfermagem através da arte: uma experiência integradora em busca da interdisciplinaridade

discentes no compromisso de discutir, problematizar, e sistematizar essa construção, gerando propostas pertinentes e viáveis para cada espaço de aprendizagem.

Nesta perspectiva, o Curso de Graduação em Enfermagem, da Universidade Federal Fronteira Sul (UFFS), campus Chapecó, com vistas a reformular seu Projeto Político Pedagógico (PPP), organizou Grupos de Trabalho (GT) para discussão e reconstrução. Semestralmente, um destes GT ficou responsável pela organização e planejamento de atividades integradoras e interdisciplinares no curso, com o objetivo de integrar, não apenas conteúdos e componentes curriculares, mas também docentes e discentes. Assim, o presente artigo objetiva relatar a vivência na construção e realização de atividades integradoras e interdisciplinares, no curso de graduação em enfermagem da UFFS.

\section{MATERIAIS E MÉTODOS}

Trata-se de um relato de experiência acadêmica, vivenciado no Curso de Graduação em Enfermagem da UFFS, campus Chapecó, com a participação de discentes e docentes. A atividade relatada neste artigo é resultado do processo de reformulação do Plano Político Pedagógico PPC, do curso de Enfermagem da referida instituição. Este processo iniciou-se no segundo semestre de 2014, momento em que foi criada uma comissão geral, composta por docentes do curso, a qual posteriormente dividiu os docentes e discentes em Grupos de Trabalhos - GTs. Cada GT ficou responsável por uma atividade, sendo que o GT “Catavento", assim denominado pelo grupo, incumbiu-se de organizar uma atividade interdisciplinar e integradora entre os componentes e fases do curso. A partir de então, realizou-se um cronograma com reuniões do GT “Catavento” para estudo e discussão da questão interdisciplinar.

Dando seguimento, no início do primeiro semestre de 2015, foi lançada a proposta da atividade interdisciplinar aos docentes e discentes. No primeiro momento, todos os discentes e docentes do curso reuniram-se no auditório da universidade, onde foram recepcionados com uma apresentação musical regida por uma das docentes do curso, fruto de um projeto de extensão desenvolvido com crianças do município. Em um segundo momento, os discentes do curso foram divididos em equipes, coordenadas por um docente tutor, sendo que em cada grupo deveria, necessariamente, ter discentes de todas as fases.

Em seguida, o tema central da atividade foi lançado "O que eu penso da enfermagem?”. Também foram apresentadas as regras e ações que cada equipe deveria planejar durante o semestre, em forma de apresentação artística cultural (teatro, música, poemas e/ou dança), refletindo o tema proposto. 
Cada equipe escolheu um nome para ser denominado e, no decorrer do semestre, organizou seus encontros, com o apoio de seus tutores, buscando planejar e organizar as atividades propostas. Diante do inverno intenso e a fim de contribuir com a população carente da região, também fez parte da atividade uma campanha de arrecadação de agasalhos e alimentos, contabilizando pontos, juntamente com a participação ativa e pontualidade nos encontros da equipe durante o semestre, fazendo a reflexão teórica e prática sobre a importância de a enfermagem estar envolvida na comunidade e prestar cuidado humanizado e holístico.

A atividade culminou ao final do semestre 2015.1, quando todo o curso de Enfermagem se reuniu novamente no anfiteatro da universidade, que foi todo decorado com a temática proposta. Neste dia, iniciaram-se as atividades com a apresentação de um vídeo envolvendo as diversas etapas da atividade interdisciplinar e integradora no decorrer do semestre, com fotos dos encontros das equipes. Após, cada equipe teve a oportunidade de realizar sua apresentação e de fazer a entrega dos agasalhos e alimentos arrecadados, que posteriormente foram doados para entidades do município.

É importante salientar que as ações desenvolvidas na atividade interdisciplinar e integradora geraram um percentual da nota do semestre, que foi somada na média final de todos os componentes curriculares do Curso.

\section{RESULTADOS E ANÁLISES}

A educação precisa ser entendida e trabalhada de forma interdisciplinar, tendo no discente um agente ativo na construção do saber. Para tanto, espera-se que o docente construa condições, dê oportunidades ao discente descobrir-se um sujeito ativo de sua aprendizagem; pois ao ser coparticipante do processo, o estudante aprenderá a planejar, a trabalhar com hipóteses e a encontrar soluções para os problemas reais (PELEIAS, et al, 2011).

Nesta perspectiva, com o intuito de possibilitar a atuação do discente como coparticipante de todo o processo de aprendizagem, realizou-se atividades integradoras e interdisciplinar no Curso de Graduação em Enfermagem da UFFS, onde primeiramente buscouse estudar a temática da interdisciplinariedade e a partir de então, criaram-se ações a serem desenvolvidas, com o envolvimento de discentes e docentes, culminando nas apresentações das atividades artística culturais e arrecadação de agasalhos.

Neste transcorrer, evidenciou-se o discente atuando em equipe, proporcionando momentos interessantes de aprendizado na prática, onde houve encontros e desencontros, diante das dificuldades em atuar no trabalho em grupo, com pensamentos diferentes, rotinas e agendas 
Descortinando enfermagem através da arte: uma experiência integradora em busca da interdisciplinaridade

divergentes para conciliar os encontros durante o semestre. Deste modo, a compreensão e vivência do estudante em enfermagem sobre o real significado de equipe é fundamental para um atendimento adequado em saúde, pois para haver qualidade e eficiência na assistência prestada é essencial a concepção coletiva do trabalho, onde a atividade integradora e interdisciplinar gera oportunidades para desenvolver e aprimorar tal habilidade.

$\mathrm{Na}$ práxis da enfermagem, o trabalho em equipe é inerente ao estabelecimento da enfermagem como profissão podendo ser reconhecido como o pilar de sustentação (MOTTA, 2001; DUARTE, ALVES, 2014). Assim, expressa-se a legitimidade de instigar os discentes para o pensar em equipe desde a sua formação, culminando na sua atuação profissional em processo que percebam o ser humano em todas as suas dimensões, respeitando-as e valorizando-as.

Historicamente, a enfermagem sustenta seus princípios em base interdisciplinar, construindo um corpo de conhecimentos, cujas mudanças sejam na pesquisa, sejam no ensino e assistência, proporcionam novas interlocuções com as ciências de qualquer natureza (MOTTA, 2001). Inclusive, no Relatório da $8^{a}$ Conferência Nacional de Saúde já preconizava, entre outras medidas, a formação dos profissionais do setor de saúde integrada a um SUS regionalizado e hierarquizado (BRASIL, 1986).

A interdisciplinaridade, tanto em sua dimensão epistemológica quanto pedagógica, está sustentada por um conjunto de princípios teóricos formulados, sobretudo por autores que analisam criticamente o modelo positivista das ciências e buscam resgatar o caráter de totalidade do conhecimento (THIESEN, 2008). Ela é um movimento importante de articulação entre o ensinar e o aprender, compreendida como formulação teórica e assumida enquanto atitude, tendo a potencialidade de auxiliar os docentes e as instituições de ensino na ressignificação do trabalho pedagógico em termos de currículo, de métodos, de conteúdos, de avaliação e nas formas de organização dos ambientes para a aprendizagem (THIESEN, 2008).

Por meio da interdisciplinaridade, a relação do todo e as partes constituintes dos objetos de estudo, superam a fragmentação do paradigma cartesiano ainda imperante nas universidades (MARIN, 2004). No entanto, é importante refletir que a tarefa de buscar definições finais para a interdisciplinaridade não seria algo propriamente interdisciplinar, mas sim disciplinar (LEIS, 2005).

É indubitável que as práticas pedagógicas inovadoras no ambiente acadêmico, surgem como oportunidade significativa de construção de práticas interdisciplinares, que pelo diálogo de diferentes disciplinas, na interseção de metodologias e estratégias, promove a integração e a construção de conhecimentos. Todavia, promover essa construção constitui um grande desafio, principalmente no que tange à postura diferenciada solicitada do docente, o qual nessa 
Descortinando enfermagem através da arte: uma experiência integradora em busca da interdisciplinaridade

perspectiva precisa se adaptar a novos paradigmas de atuação pedagógica (TREML, PEREIRA, SCHOLZE, 2011).

Com o desenvolvimento da atividade interdisciplinar no curso de Enfermagem foi possível integrar não apenas conteúdos e componentes curriculares do curso, como também integrar discentes e docentes no processo de construção das ações propostas no decorrer do semestre. Vários discentes relataram que puderam estabelecer vínculo com colegas que conheciam apenas de vista nos corredores, sendo um importante momento de integração no curso. Mais do que a criação de vínculos entre discentes e docentes, a atividade proporcionou profunda reflexão nos grupos acerca do tema “O que eu penso da Enfermagem?”.

Porém, a atividade também proporcionou certo desconforto para alguns discentes, que no primeiro momento, não apreciaram a ideia devido às dificuldades em atuar em equipe, mas também devido ao fato de que tiveram que sair do seu espaço de conforto, ou seja, tiveram que correr atrás das ações, não as recebendo já prontas, como a grande maioria estava acostumada a vivenciar no cotidiano das aulas teóricas, estranhando inclusive a aula com a participação de todos no anfiteatro. No entanto, após a conclusão da atividade, os discentes avaliaram como algo positivo e que também deveria ser dada continuidade ao processo nos demais semestres, mas com necessidade de novas configurações na proposta, como proporcionar horários de encontros no próprio calendário do curso e com menor número de atividades devido às demandas dos componentes curriculares no decorrer do semestre.

Os resultados foram surpreendentes, a começar pelas próprias apresentações artísticas culturais, onde revelaram-se vários talentos que estavam desconhecidos até então. Desvelaram-se assim acadêmicos de enfermagem compositores de poemas, cantores, dançarinos e artistas que interpretaram de forma extraordinária seus papéis nas atividades teatrais, o que despertou inclusive o interesse de alguns familiares, que se deslocaram até o campus universitário para assistir as apresentações de seus filhos.

Desta forma, além de proporcionar integração entre docentes e discentes, bem como revelar novos talentos e de realizar interação da família e comunidade com o curso e universidade, através da atividade interdisciplinar e integradora também foi possível proporcionar um momento de aprendizado sobre a enfermagem através da arte de forma lúdica e agradável, com risadas, música, dança, balões e até sessões de choro e reflexões nas encenações que surgiram sobre a temática, despertando a criatividade nos envolvidos.

As diversas apresentações giraram em torno do tema central da atividade e, desta forma, as equipes, com o apoio de seus tutores, revelaram o que pensavam sobre a enfermagem através da arte, que realmente surpreendeu todos os participantes em cada apresentação realizada. Nas 
apresentações, surgiram aspectos relacionados às diversas áreas de atuação da enfermagem, como a atenção à saúde nas etapas do ciclo vital, a integralidade do cuidado, aspectos éticos da profissão, empatia, espiritualidade, entre outros. Todavia, ficou evidente que algumas equipes, apesar das apresentações artísticas muito criativas e inovadoras, não tinham um pleno conhecimento do que vinha a ser a enfermagem, revelando conceitos equivocados quanto ao ser enfermeiro.

Os resultados apresentados pelas equipes permitiram diversas reflexões ao corpo docente do curso, revelando algumas falhas no processo pedagógico quanto à importância do papel do enfermeiro na equipe de saúde e sua atuação na comunidade. Desta forma, a atividade proporcionou integração entre docentes e discentes de diferentes fases, mas também despertou profunda reflexão sobre o papel da enfermagem e um olhar crítico para o próprio PPC, identificando potencialidades, fragilidades e oportunidades de mudanças e melhorias, tornando o discente um ator ativo neste processo.

\section{CONSIDERAÇÕES FINAIS}

Por meio desta experiência ficou evidente que é importante e possível ter a participação do discente na construção das diretrizes curriculares e reformulação do PPC de seu próprio curso, o que pode ser realizado de forma criativa, artística, integrativa e interdisciplinar. Também ficou em destaque a importância de haver maior integração entre os docentes e discentes de todo o curso.

No entanto, isso exige uma diferente postura e envolvimento por parte dos discentes e docentes, pois a formação generalista do enfermeiro, envolvendo diferentes dimensões, necessita considerar que o ensino não pode ser repetição e exposição de conteúdos. Nesta perspectiva, cabe às instituições de ensino buscar romper com a visão do paradigma conservador, ousando trilhar novos caminhos, investindo em experiências interdisciplinares no curso, que irá demandar bastante trabalho de todos os envolvidos, mas que valerá a pena com os resultados satisfatórios.

É importante refletir sobre a formação acadêmica, pesquisar e publicar os achados, a fim de fornecer subsídios para a elaboração de propostas que possam também ir ao encontro das reais necessidades dos discentes e docentes, construindo, renovando e modificando a prática pedagógica. Assim, sugere-se o compartilhar de novas experiências com a utilização da interdisciplinaridade, integração e arte, a fim de incentivar outras universidades e cursos a se despertarem para tal ação. 
Descortinando enfermagem através da arte: uma experiência integradora em busca da interdisciplinaridade

\section{REFERÊNCIAS}

BRASIL, Ministério da Saúde. $8^{a}$ Conferência Nacional de Saúde. Brasília: Ministério da Saúde; 1986. Disponível em: < http://conselho.saude.gov.br/biblioteca/relatorios/relatorio 8.pdf> . Acesso em 28 Jul 2016.

CURY, A.J. Pais brilhantes, professores fascinantes. Rio de Janeiro: Sextante; 2003.

DUARTE, M.G; ALVES, M.S. Trabalho em equipe/proximidade do paciente: elementos da práxis de Enfermeiras na terapia intensiva. Rev Enferm UFSM, v.4, n.1, p.144-151, 2014. Disponível: < http://periodicos.ufsm.br/reufsm/article/viewFile/9059/pdf $>$. Acesso em $25 \mathrm{Jul}$ 2016.

LEIS, H.R. Sobre o conceito de interdisciplinaridade. Caderno de Pesquisa interdisciplinar em Ciências Humanas, v.6, n.73, p.1-23, 2005. Disponível em: https://periodicos.ufsc.br/index.php/cadernosdepesquisa/article/view/2176/4455

MORIN, E. A cabeça bem-feita: repensar a reforma, reformar o pensamento. Tradução de Eloá Jacobina. Rio de Janeiro: Bertrand Brasil; 2004.

MOTTA, P.R. Desempenho em equipes de saúde: manual. Rio de Janeiro (RJ): FGV; 2001.

PELEIAS, I.R, et al. Interdisciplinaridade no ensino superior: análise da percepção de professores de controladoria em cursos de ciências contábeis na cidade de são Paulo. Avaliação, v.16, n.3, p. 499-532, 2011. Disponível em:<

http://www.scielo.br/pdf/aval/v16n3/v16n1a02.pdf>. Acesso em 28 Jul 2016.

RANGEL, R.F, et al. Avanços e perspectivas da atuação do enfermeiro em estratégia saúde da familia. Cogitare Enferm, v.16, n.3, p.498-504, 2011. Disponível em:< https://www.researchgate.net/publication/271715013 AVANCOS E PERSPECTIVAS DA ATUACAO DO ENFERMEIRO EM ESTRATEGIA SAUDE DA FAMILIA $>$. Acesso em 25 Jul 2016.

TANAKA, L.H; LEITE, M.M.J. Processo de trabalho do enfermeiro: visão de professores de uma universidade pública. Acta. Paul. Enfermagem, v.21, n.3, p.481-6, 2008. Disponível em:< http://www.scielo.br/pdf/ape/v21n3/pt 16.pdf >. Acesso em 28 Jul 2016.

THIESEN, J.S. A interdisciplinaridade como um movimento articulador no processo ensinoaprendizagem. Rev. Bras. Educ, v.13, n.39, p.545-98, 2008. Disponível em:

$<$ http://www.scielo.br/scielo.php?pid=S1413-24782008000300010\&script=sci arttext $>$. Acesso em 25 Jul 2016.

TREML, E.E.Z; PEREIRA, L; SCHOLZE, E. Prática Pedagógica Integradora nas Disciplinas do Curso de Ciências Contábeis de uma Universidade Comunitária do Norte de Santa Catarina: uma experiência interdisciplinar num devir. Anais XXXV Encontro da ANPAD, Rio de Janeiro - 
Descortinando enfermagem através da arte: uma experiência integradora em busca da interdisciplinaridade

RJ, 2011. Disponível em: http://www.anpad.org.br/admin/pdf/EPQ2089.pdf. Acesso em 25 Jul 2016.

VASCONCELOS, E.M. Complexidade e pesquisa interdisciplinar:epistemologia e metodologia operativa. Petrópolis (RJ): Vozes; 2002. 